\title{
Patient Experience and Satisfaction of Orthodontic Retention after Treatment in Saudi Arabia
}

\author{
Mohammad Aldosari ${ }^{1}$, Waad Alrahmah ${ }^{* 2}$, Fadila Al Hammad ${ }^{3}$, Rahaf Alhmadi ${ }^{4}$, Shahzeb Ansari ${ }^{5}$, \\ Khames Alzahrani ${ }^{6}$
}

${ }^{1}$ Department of Pediatric Dentistry and Orthodontics, College of Dentistry, King Saud University, P.O. Box 60169 Riyadh 11545, Saudi Arabia

${ }^{2}$ General Dentist, Riyadh Elm University, Alkharj, Saudi Arabia

${ }^{3}$ General Dentist, Ram Medical Company, Eastern Province, Saudi Arabia

${ }^{4}$ General Dentist, Ibn Sina College, Jeddah, Saudi Arabia

${ }^{5}$ Instructor, Department of Preventive, Riyadh Elm University, Riyadh, Saudi Arabia

${ }^{6}$ BDS, PGD Endo, Ministry of Health, Saudi Arabia

Corresponding author: Waad Alrahmah; wa.alrhamah@gmail.com

Received 10 August 2021;

Accepted 28 August 2021;

Published 02 September 2021

\begin{abstract}
Background: Orthodontics treatment aimed to make patient satisfied about treatment result starting from appearance to the function. Orthodontic retention is consider as important stage to stabilize the result of orthodontic treatment and avoid relapse that caused by normal age changes. Methods: A cross-sectional study performed through patient questionnaires. A total of 450 patients were included in the study. The questionnaire included 19 questions. The questionnaire consisted of question about socio-demographic status of the respondents such as age, gender, also included question about the type of retainer fixed or removable retainers that were used, duration of wearing retainer and Retention protocol. Result: In our study majority of the participants were females (87.3\%), and 55.3\% belonged to the 20-25 years age group. The fixed orthodontic related history showed $59.8 \%$ had undergone the treatment for 1 to 3 years and $31.6 \%$ of the participants reported that they had removed the fixed braces for more than five years. Among these participants, $89.5 \%(n=34)$ reported that the fascia (space) closed between the upper frontal teeth after Frenectomy, and 65.8\% $(\mathrm{n}=25)$ agreed that spaced between the two upper front teeth still closed after removing the retainer. Conclusion: The study findings showed that the majority of the participants were aware of the frequency and duration of wearing retainers but didn't completely adhere to the instructions given by the orthodontists and/or dentists. The major reason for not using retainers was difficulty in speaking or uncomfortableness.
\end{abstract}

Keywords: Removable Retainer, Fixed Retainer, Compliance, Relapse, Satisfaction.

\section{Introduction}

Orthodontics is the science that deals with the abnormalities of facial growth, dentition development and occlusion, with diagnosis, interception and treatment ${ }^{[1]}$. The main objective of orthodontic treatment is to achieve an esthetically appropriate natural, stable and well-functioning occlusion, in other words we may call it "ideal" occlusion ${ }^{[2]}$. Orthodontic retention is the final stage of orthodontic treatment and aims to maintain the teeth in their corrected positions after the completion of orthodontic tooth movement and the sound orthodontic treatment planning and the achievement of appropriate occlusal and soft tissue treatment goals can help to minimise orthodontic relapse ${ }^{[3]}$. Once active orthodontic treatment has been finished, teeth tend to return to their original positions. This phenomenon is called as Relapse ${ }^{[4]}$. The importance of maintaining the tooth alignment after orthodontic treatment was recognized as early as 1904 to avoid relapse ${ }^{[5]}$. Orthodontic relapse is a common finding after successful orthodontic treatment ${ }^{[6,7]}$. After finishing the active treatment, teeth tend to relapse toward the original positions due to pressures exerted by the surrounding tissues and the continued growth, ${ }^{[8,9]}$ which makes the retention of the corrected positions a challenging phase for the orthodontist ${ }^{[10]}$. It has been reported that a varying degree of compensation in the lower dental arch occurred during the post-retention period in $70-90 \%$ of the orthodontically treated cases, whereas the observed changes in the upper arch were milder ${ }^{[11]}$. A number of variables were correlated with orthodontic relapse 
such as retention protocol, patient compliance, age and final occlusion after therapy ${ }^{[11]}$.

These variables are likely to behave in conjunction to cause a relapse in the large majority of patients ${ }^{[12]}$. However, there were also many variations in retention protocols concerning retainer type selection and retention length. For example, removable vacuum-formed retainers in the UK were most frequently used to retain the maxillary dental arch ${ }^{[13]}$. Australia and New Zealand ${ }^{[14]}$. While a fixed and removable retainer combination was widely used in Norway for maxillary dentition ${ }^{[15]}$. In addition, orthodontists operating in the same nation had significant distinctions ${ }^{[16]}$. Noted that "individual orthodontists used removable retainers very often or rarely" This was probably due to the reality that a retention method choice was mainly based on personal preference, experience and other non-scientific criteria ${ }^{[4]}$. Orthodontists came up with different methods, appliances and regimens for retention, but there is no consensus on how long retainers should be worn ${ }^{[17]}$.

While several studies have shown that fixed retainers are safe and effective over the long term for most patients ${ }^{[16,18]}$. Latest study found that the only predictive factors which significantly increase the risk of alignment instability are not using a fixed retainer and years without retention ${ }^{[19,20]}$. Therefore the primary aim of this study was to assess the satisfaction of patients and expectation about post-orthodontic retention. Patient satisfaction after orthodontic treatment often tends to be affected by a number of factors such as gender, age, duration of treatment, patient knowledge, compliance, doctor-patient relationship and dentofacial improvement also seem to contribute to the level of satisfaction ${ }^{[21,22]}$. Overall satisfaction of patients with their orthodontic experience is closely related to their expectations of stability ${ }^{[23]}$. Retention is an necessary and mandatory component of orthodontic treatment and could be an important factor in determining the long term patient satisfaction with the orthodontic treatment ${ }^{[2]}$.

Kaplan suggested that patients should be informed of the high chance that some relapse will occur after appliances are removed and the normal changes that occur over time. In this way, patients become an essential part of the decision-making process, besides the orthodontist, regarding the appropriate duration of retention procedures. Undoubtedly, successful preservation of orthodontic outcomes is most effective if patients accept responsibility for wearing and maintaining appropriate retention appliances ${ }^{[5]}$. Consequently, successful preservation of orthodontic outcomes can be accomplished if patients take responsibility for the maintenance and wearing the retainers ${ }^{[23]}$. Wong and Freer also reported that over $50 \%$ of patients admitted that they did not wear retainers as instructed, with the most common reasons being discomfort and forgetfulness ${ }^{[24]}$.

\section{Subjects and Methods}

This is a cross-sectional observational study design conducted from March 10, 2020-May 20, 2021 to assess the satisfaction of patients and expectation about post-orthodontic retention in Saudi Arabia. The questionnaire is taken from previous questionnaire ${ }^{[25]}$. The questionnaire included 19 questions, mainly containing multiplechoice questions and was consisted seven sections which organized for orthodontic patients who had already done with orthodontic treatment. Inclusion criteria are as follows: patients aged between 15 years and 60 years, Female and Male, agree to participate, from Saudi Arabia. Any participants were younger than 15 years or older than 60, disagree to participate, outside of Saudi Arabia or not Saudi were excluded from our study.

\section{Statistical analyses and sample size calculation}

Data were represented in the form of frequencies (number of responders) and valid percentages for categorical variables. Mean (SD) and frequency and percentage were calculated. SPSS (Statistical Package for the Social Science; IBM Corp, Armonk, NY, USA) was used to perform all statistical calculations, version 23 for Microsoft Windows. Considering a confidence level of $95 \%$, a marginal error of $5 \%$. A total of 450 eligible participants responded to the questionnaire and examination was done were included in the statistical analysis.

\section{Ethical considerations}

All participants written consents from their parents and willing to be interviewed and examined if they agree or not to take part in the study. Only those who agreed to participate were included. Before conducting any study-related procedures, ethical approval was obtained from Research Ethics Committee at Riyadh Elm University, Saudi Arabia.

\section{Results}

In our study majority of the participants were females (87.3\%), and $55.3 \%$ belonged to the 20-25 years age group [Table 1]. The fixed orthodontic related history showed $59.8 \%$ had undergone the treatment for 1 to 3 years and $31.6 \%$ of the participants reported that they had removed the fixed braces for more than five years. It was reported by $8.4 \%(n=38)$ that they had undergone Frenectomy before the initiation of fixed orthodontic treatment. Among these participants, $89.5 \%(n=34)$ reported that the fascia (space) closed between the upper frontal teeth after Frenectomy, and $65.8 \%$ $(n=25)$ agreed that spaced between the two upper front teeth still closed after removing the retainer. There was no statistically significant association found between fixed orthodontic treatment history and the age of the participants $(\mathrm{p}<0.05)$ [Table 2].

Table 1: Socio-demographics characteristics of the study participants $(n=450)$

Baseline characteristics of participants $(n=450)$

\begin{tabular}{|l|l|l|l|}
\hline \multicolumn{2}{|l|}{ Baseline characteristics of participants $(\mathbf{n}=\mathbf{4 5 0})$} & Frequency & Percent \\
\hline \multirow{4}{*}{ Age } & $<20$ & 56 & 12.4 \\
\cline { 2 - 4 } & $20-25$ & 249 & 55.3 \\
\cline { 2 - 4 } & $26-30$ & 90 & 20.0 \\
\cline { 2 - 5 } & $>30$ & 55 & 12.2 \\
\hline \multirow{2}{*}{ Gender } & Female & 393 & 87.3 \\
\cline { 2 - 4 } & Male & 57 & 12.7 \\
\hline
\end{tabular}

Table 2: Orthodontic treatment related factors based on age of the participants $(n=450)$

\begin{tabular}{|c|c|c|c|c|c|c|c|c|}
\hline & & & \multicolumn{4}{|c|}{ Age (years) } & \multirow[t]{2}{*}{ Total } & \multirow{2}{*}{$\begin{array}{l}\text { P value } \\
\left(X^{2} \text { value }\right)\end{array}$} \\
\hline & & & $<20$ & $20-25$ & $26-30$ & $>30$ & & \\
\hline \multirow{2}{*}{$\begin{array}{l}\text { Duration of fixed orthodontic } \\
\text { treatment }\end{array}$} & \multirow{2}{*}{$<=1$ year } & $\mathrm{N}$ & 14 & 32 & 13 & 12 & 71 & \multirow{2}{*}{$\begin{array}{l}0.201 \\
(8.548)\end{array}$} \\
\hline & & $\%$ & $19.7 \%$ & $45.1 \%$ & $18.3 \%$ & $16.9 \%$ & $15.8 \%$ & \\
\hline
\end{tabular}




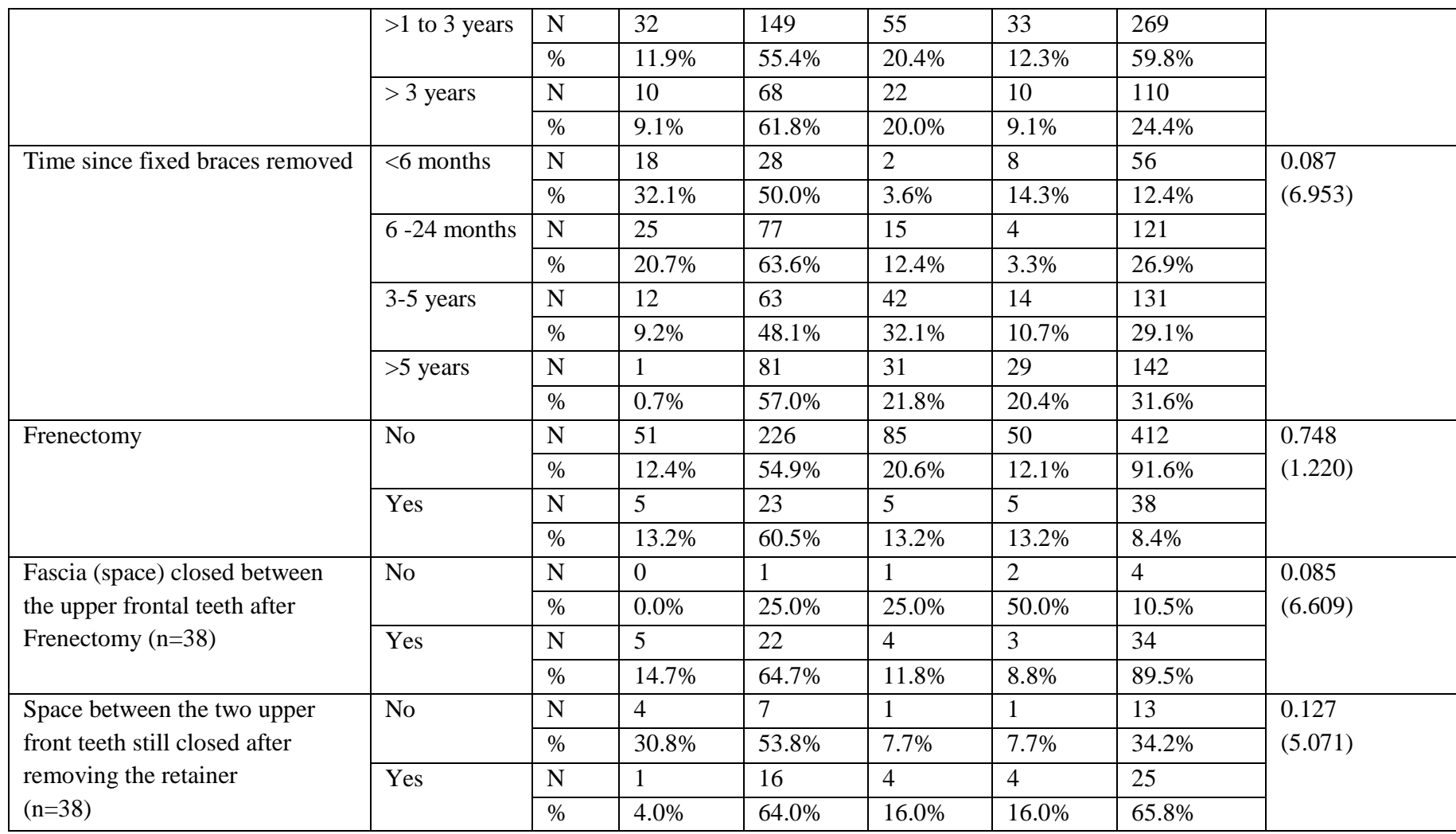

However, there was a statistically significant association seen between the gender of the participants and the duration of the fixed orthodontic treatment. It was found that females underwent the treatment for a longer duration (> 3 years) $(90.9 \%)$ compared to males $(9.1 \%) \quad(\mathrm{p}=0.020)$, and Frenectomy was performed significantly higher in females $(60.5 \%)(\mathrm{p}<0.001)$ [Table 3].

Table 3: Orthodontic treatment related factors based on gender of the participants $(n=450)$

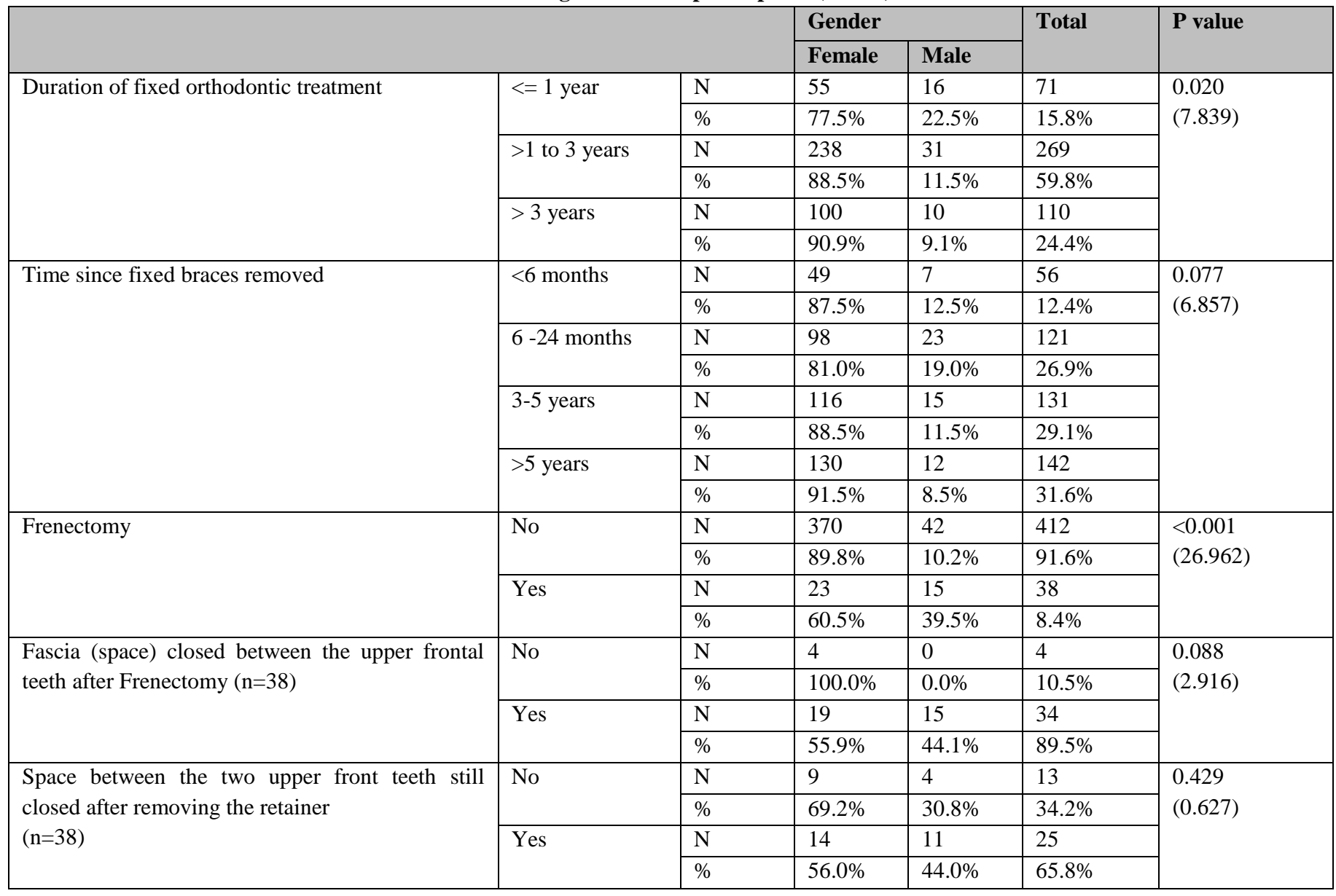


It was reported by $10.9 \%$ that they didn't use a retainer after removing fixed braces, and $27.3 \%(\mathrm{n}=123)$ used stainless steel bonded retainer for both upper and lower arch [Figure 1].

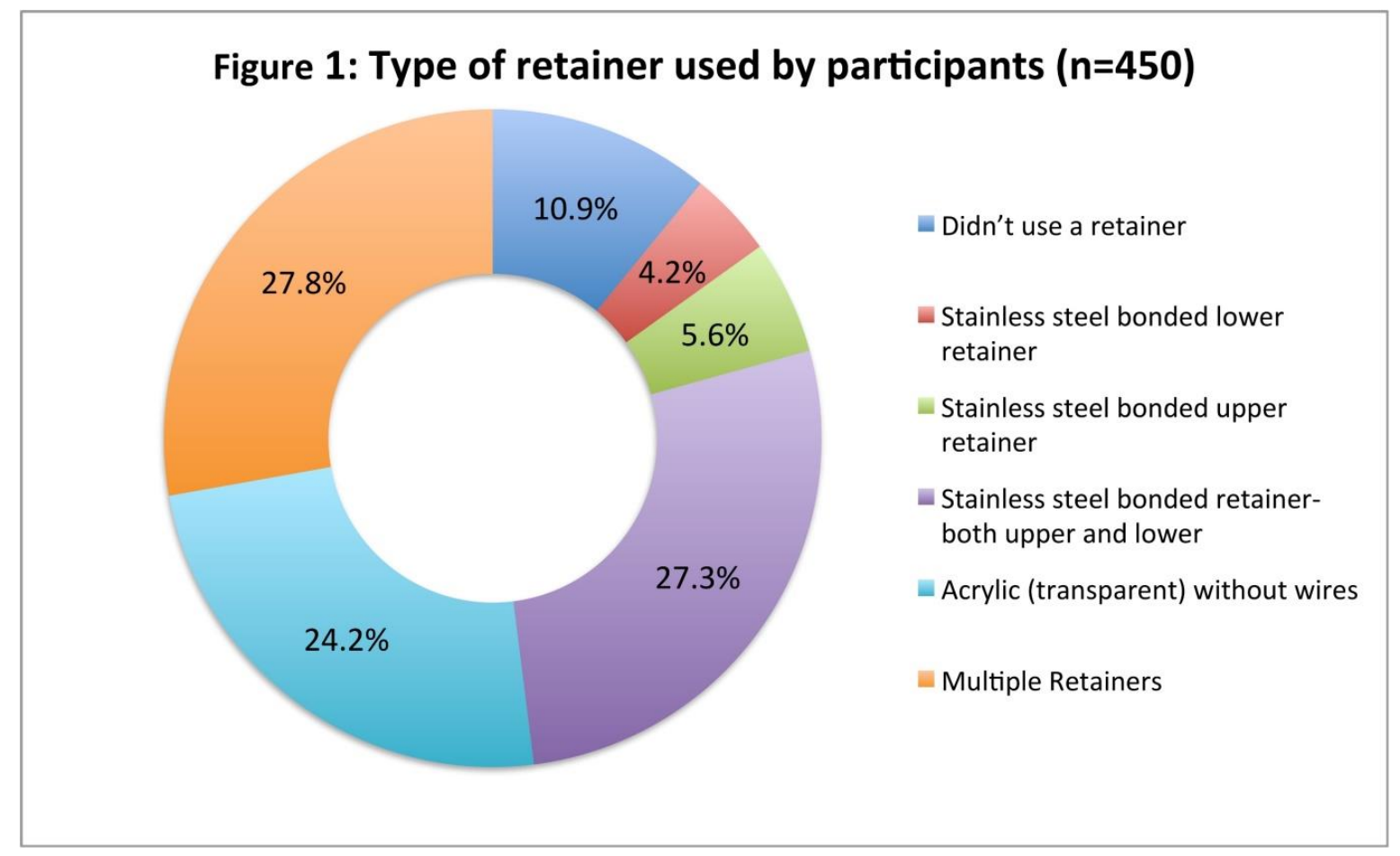

When we assessed the relationship of practices related to retainer used, it was reported by $70.3 \%$ that their orthodontist advised them to use the retainer for the whole day (both day and night), and $49.5 \%$ reported that it was instructed to be used only during the night. The frequency of wearing retainer showed that $5 \%$ never used retainer and $49.4 \%$ used it every day as advised by the orthodontist. The most reported reason for not using retainer difficulty to speak or no comfortable to use, and $12.5 \%$ mentioned the reason as they lost or damaged it. It was found that $38.2 \%$ replaced the retainer at least one time since it was first made available, and the major reason for replacing it was 'losing it' (43.1\%). Only $21.4 \%$ reported that they made a follow-up appointment after completing fixed orthodontic treatment or after placing a retainer. It was reported by $40.1 \%$ of the participants that found noticeable changes in the alignment of teeth from the corrected alignment (after removing fixed braces), and the changes were more seen during 7-12 months (39.1\%). However, there was no statistically significant association seen between practices related to retainer and baseline characteristics of the participants $(\mathrm{p}>0.05)$ [Table 4].

Table 4: Practices related to retainer and its relationship with age and gender of the participants.

\begin{tabular}{|c|c|c|c|c|}
\hline & & & Age & Gender \\
\hline \multirow{2}{*}{$\begin{array}{l}\text { Instructed to wear your distance keeper full } \\
\text { time day and night (including bedtime) }\end{array}$} & No & $119(29.7 \%)$ & \multirow{2}{*}{$\begin{array}{l}0.712 \\
(1.374)\end{array}$} & \multirow{2}{*}{$\begin{array}{l}0.905 \\
(0.014)\end{array}$} \\
\hline & Yes & $282(70.3 \%)$ & & \\
\hline \multirow{2}{*}{$\begin{array}{l}\text { Instructed to wear the distance keeper only at } \\
\text { night }\end{array}$} & No & $201(50.1 \%)$ & \multirow{2}{*}{$\begin{array}{l}0.183 \\
(4.851)\end{array}$} & \multirow{2}{*}{$\begin{array}{l}0.338 \\
(0.918)\end{array}$} \\
\hline & Yes & $200(49.9 \%)$ & & \\
\hline \multirow[t]{6}{*}{ Frequency of wearing retainer } & Never & $20(5.0 \%)$ & \multirow{6}{*}{$\begin{array}{l}0.483 \\
(14.561)\end{array}$} & \multirow{6}{*}{$\begin{array}{l}0.467 \\
(4.596)\end{array}$} \\
\hline & Once in a month & $11(2.7 \%)$ & & \\
\hline & Once in a week & $10(2.5 \%)$ & & \\
\hline & Several days in a week & $140(34.9 \%)$ & & \\
\hline & Every day & $198(49.4 \%)$ & & \\
\hline & Others & $22(5.5 \%)$ & & \\
\hline \multirow{4}{*}{$\begin{array}{l}\text { Duration of wearing retainer } \\
(\mathrm{n}=381)\end{array}$} & Never & $18(4.7 \%)$ & \multirow{4}{*}{$\begin{array}{l}0.621 \\
(7.154)\end{array}$} & \multirow{4}{*}{$\begin{array}{c}1902 \\
(0.593)\end{array}$} \\
\hline & $1-3$ months & $84(22.0 \%)$ & & \\
\hline & $3-6$ months & $77(20.2 \%)$ & & \\
\hline & 6-12 months & $202(53.0 \%)$ & & \\
\hline \multirow{6}{*}{$\begin{array}{l}\text { Reasons for not wearing retainer as advised by } \\
\text { orthodontist } \\
(\mathrm{n}=401)\end{array}$} & Don't like it & $15(3.7 \%)$ & \multirow{6}{*}{$\begin{array}{l}0.192 \\
(19.507)\end{array}$} & \multirow{6}{*}{$\begin{array}{l}0.543 \\
(4.045 \\
)\end{array}$} \\
\hline & Forget to wear it & $80(20 \%)$ & & \\
\hline & Lost or damaged & $50(12.5 \%)$ & & \\
\hline & Doesn't fit anymore & $39(9.7 \%)$ & & \\
\hline & Difficulty to speak or uncomfortable & $154(38.4 \%)$ & & \\
\hline & Other reasons & $63(15.7 \%)$ & & \\
\hline \multirow{2}{*}{$\begin{array}{l}\text { Replaced retainer since it was first made } \\
\text { available after removing braces }\end{array}$} & No & $248(61.8 \%)$ & \multirow{2}{*}{$\begin{array}{l}0.058 \\
(7.475)\end{array}$} & \multirow{2}{*}{$\begin{array}{l}0.640 \\
(0.218)\end{array}$} \\
\hline & Yes & $153(38.2 \%)$ & & \\
\hline
\end{tabular}




\begin{tabular}{|c|c|c|c|c|}
\hline \multirow{4}{*}{$\begin{array}{l}\text { Reason for replacing it } \\
(\mathrm{n}=153)\end{array}$} & Doesn't fit anymore & $35(22.9 \%)$ & \multirow{4}{*}{$\begin{array}{l}0.669 \\
(6.693)\end{array}$} & \multirow{4}{*}{$\begin{array}{l}0.804 \\
(0.989)\end{array}$} \\
\hline & Lose it & $66(43.1 \%)$ & & \\
\hline & Damaged & $46(30.1 \%)$ & & \\
\hline & Other reasons & $6(3.9 \%)$ & & \\
\hline \multirow{2}{*}{$\begin{array}{l}\text { Attended follow up appointment after placing } \\
\text { retainer }\end{array}$} & No & $315(78.6 \%)$ & \multirow{2}{*}{$\begin{array}{l}0.575 \\
(1.987)\end{array}$} & \multirow{2}{*}{$\begin{array}{l}3.843 \\
(0.050)\end{array}$} \\
\hline & Yes & $86(21.4 \%)$ & & \\
\hline \multirow[t]{3}{*}{ Noticed changes in the alignment } & No changes at all & $71(17.7 \%)$ & \multirow{3}{*}{$\begin{array}{l}0.855 \\
(2.618)\end{array}$} & \multirow{3}{*}{$\begin{array}{l}0.342 \\
(2.146)\end{array}$} \\
\hline & Minor unnoticeable changes & $169(42.1 \%)$ & & \\
\hline & Noticeable changes & $161(40.1 \%)$ & & \\
\hline \multirow{5}{*}{$\begin{array}{l}\text { Time taken to see the changes in alignment } \\
(\mathrm{n}=330)\end{array}$} & $1-3$ months & $82(24.8 \%)$ & \multirow{5}{*}{$\begin{array}{l}0.084 \\
(19.186)\end{array}$} & \multirow{5}{*}{$\begin{array}{l}0.722 \\
(2.076)\end{array}$} \\
\hline & $4-6$ months & $73(22.1 \%)$ & & \\
\hline & 7-12 months & $129(39.1 \%)$ & & \\
\hline & $>1$ year & $38(11.5 \%)$ & & \\
\hline & Don't remember & $8(2.4 \%)$ & & \\
\hline
\end{tabular}

When we asked the participants how often they should wear a retainer, the majority of them $(92.3 \%)$ agreed that it should be worn, which was significantly more reported by the participants of age group 20-25 years and 26-30 years $(\mathrm{p}=0.002)$. The most common reason that participants thought for seeing the changes in the alignment (relapse) after correction of the malocclusion was 'not earing the removable retainer as advised by the orthodontist, which was comparatively more reported by male than females $(\mathrm{p}=0.001)$ [Table 5].

Table 5: Perceptions related to retainer used and its relationship with age and gender

\begin{tabular}{|c|c|c|c|c|}
\hline & & & \multicolumn{2}{|c|}{$P$ value $\left(X^{2}\right)$} \\
\hline & & & Age & Gender \\
\hline \multirow{4}{*}{$\begin{array}{l}\text { How often should the } \\
\text { retainer be worn }\end{array}$} & Once a month & $3(0.7 \%)$ & \multirow{4}{*}{$\begin{array}{l}0.002 \\
(26.353)\end{array}$} & \multirow{4}{*}{$\begin{array}{l}0.342 \\
(3.343)\end{array}$} \\
\hline & Once in a week & $7(1.7 \%)$ & & \\
\hline & Everyday & $370(92.3 \%)$ & & \\
\hline & Other & $21(5.2 \%)$ & & \\
\hline \multirow{4}{*}{$\begin{array}{l}\text { Reasons for seeing the } \\
\text { changes in alignment } \\
(n=330)\end{array}$} & Not wearing the advised removable retainer & $144(43.6 \%)$ & \multirow{4}{*}{$\begin{array}{l}0.754 \\
(6.324)\end{array}$} & \multirow{4}{*}{$\begin{array}{l}0.001 \\
(16.168)\end{array}$} \\
\hline & The orthodontist didn't give me a fixed retainer & $60(18.2 \%)$ & & \\
\hline & Due to presence oral habits like tongue thrusting, thumb sucking & $26(7.9 \%)$ & & \\
\hline & Other reasons & $100(30.3 \%)$ & & \\
\hline
\end{tabular}

\section{Discussion}

In fixed orthodontic treatment [FOT], retention is crucial for preventing relapse of the final occlusal outcome. However, some degrees of relapse are unavoidable until appropriate retention protocol is followed after removing the active appliances ${ }^{[1]}$. Evidence shows that patient compliance decreases as FOT progress, and poor compliance to orthodontist's instructions related to the use of retainers can often compromise the achieved orthodontic outcomes ${ }^{[2]}$. There is a lack of information regarding the use of retainers and patients' satisfaction and expectation following FOT in the KSA. Hence this study aimed to assess patients' satisfaction and expectation about post-orthodontic retention. The study findings showed that approximately $60 \%$ of participants reported that they underwent FOT for duration of 1-3 years. There is no consensus about the actual treatment duration of using active fixed appliances for correction of malocclusion in literature. However, a meta-analysis has reported that the mean duration of orthodontic treatment to be 19.9 months ${ }^{[3]}$. Several factors could influence FOT's duration, including gender, type of malocclusion (overbite, crowding, etc.), pre-treatment ANB value, extractions, patient compliance, the time between appointments, and oral hygiene status, and other sociodemographic characteristics ${ }^{[4,7]}$. Among these factors, patients' compliance with orthodontist's instructions regarding the use of retainers is crucial in the stability after FOT.

The presence of maxillary and/or mandibular midline diastema due to high frenal attachment may compromise the closure of the space between the frontal teeth ${ }^{[8]}$. Frenectomy is indicated in such patients to facilitate closure of the midline diastema in the course FOT, which can be performed before, during, and after the closure of the space depending on the individual case ${ }^{[9]}$. In our study, only $8.4 \%$ had undergone frenectomy, and among this, approximately $66 \%$ reported that space between was closed. Our study findings showed that the majority of the participants reported that they were instructed to wear retainer full time and nearly half of the participants. After removing active appliances, the application of retainer would minimize the changes caused by growth and enables reorganization of the tissue, thus allowing neuromuscular adaptation to the corrected tooth position ${ }^{[10]}$. A study conducted by Ren et al. reported that a longer duration of retainer use was found to be a protective factor for relapse ${ }^{[11]}$. Orthodontists use a different form of retainers that includes both fixed (bonded) and removable (acrylic), vacuum formed, and spring retainers ${ }^{[12]}$. An orthodontist commonly prefers fixed bonder retainers (FBR) as they have better esthetics, lifelong retention, good patient acceptance ${ }^{[13]}$. In our study, the majority of the participants used FBR, and nearly half of them reported that they used it every day. When asked about the reasons for not wearing retainers, the major reason was difficult to speak or uncomfortableness. The stability of orthodontic treatment is hugely dependent on patient satisfaction and compliance to instructions given by orthodontists ${ }^{[14]}$. Our study findings showed that $78.6 \%$ didn't attend follow-up appointments, and $82.3 \%$ noticed some changes in the alignment from the corrected tooth position. Adhering to the use of retainers is often challenging for the patients especially if they are removable retainers and for this reason, the majority of the orthodontist suggests extended wear of 
bonded retainers as they will minimize the changes in the alignment after orthodontic correction ${ }^{[15]}$. A survey done in Saudi Arabia among orthodontists reported that the majority of them preferred Hawley's retainers for maxillary arch and bonded lingual retainers for mandibular arch ${ }^{[16]}$. Removable retainers for the maxillary arch will help the orthodontists involve the patient in taking responsibility for maintaining the treatment outcomes. Regardless of the type, retainers should not cause any pain or discomfort and should be acceptable for people to wear. Any harm or discomfort caused by the retainer would make patients not use it and thus compromising the maintenance of achieved outcomes from FOT, leading to relapse. However, the duration and frequency of retainer wear are still controversial topics among orthodontists. Majority of the orthodontist has the view that optimal time interval for the first retention period should be one year ${ }^{[17,18]}$. According to Parker, retention of at least 232 days is essential for the fibers surrounding the tooth's root area to regenerate and provide stability after removing active orthodontic appliances ${ }^{[19]}$. The study findings highlight that majority of the participants were instructed to use retainers by their orthodontists and thus signifies the importance of communication between the patient and dentist or orthodontists regarding orthodontic retention (OR). The patient should be educated about the importance of OR in the maintenance of the orthodontic treatment outcomes and its relationship with relapse. Furthermore, the compliance of the patient is wearing removable retainers, and the drawbacks of fixed retainers make it essential to plan to follow up after treatment. Thus, patients should be instructed for appropriate aftercare and follow up systematically and responsibly with dentists or orthodontists.

\section{Conclusion}

The study findings showed that the majority of the participants were aware of the frequency and duration of wearing retainers but didn't completely adhere to the instructions given by the orthodontists and/or dentists. The major reason for not using retainers was difficulty in speaking or uncomfortableness. More than three-fourths of the participants agreed that they didn't attend a follow-up appointment after the retainer application. Orthodontists and/or dentists should give sufficient information related to orthodontic retention and provide appropriate instructions regarding the use and maintenance of retainers to patients in order to increase compliance.

\section{Ethics approval}

Institutional research ethics board approval was acquired before conducting any study-related procedures. A statement was included at the beginning of the questionnaire clarifying that the participation in this study is voluntary and that collected data will be anonymous and will only be used for this study.

\section{Conflicts of Interest}

The authors have no conflicts of interest to declare.

\section{Source of Funding}

This study did not receive any specific grant from funding agencies in the public, commercial, or not-for-profit sectors.

\section{References}

[1] Mitchell, L., Jenkins, F., Littlewood, S. and NelsonMoon, Z. (2013). An introduction to orthodontics. p.2.

[2] Bondemark L, Holm A-K, Hansen K, Axelsson S, Mohlin B, Brattstrom V. Long-term Stability of Orthodontic Treatment and Patient Satisfaction. Angle Orthod. 2007;77(1).

[3] Johnston CD, Littlewood SJ. Retention in orthodontics. Br Dent J. 2015;218(3):119-22.

[4] Lai, C.S., Grossen, J.M., Renkema, A.M., Bronkhorst, E., Fudalej, P.S. and Katsaros, C. (2014) Orthodontic retention procedures in Switzerland. Swiss Dental Journal, 124, 655-661.

[5] Kaplan, H. (1988) The logic of modern retention procedures. American Journal of Orthodontics and Dentofacial Orthopedics, 93, 325-340.

[6] Horowitz SL, Hixon EH. Physiologic recovery following orthodontic treatment. American Journal of Orthodontics 1969;55:1-4.

[7] Graber TM. Orthodontics - principles and practice. 3rd ed. Philadelphia: Saunders; 1972: 597-608. 3.

[8] Little RM, Riedel RA, Artun J. An evaluation of changes in mandibular anterior alignment from 10 to 20 years postretention. Am J Orthod Dentofac Orthop. 1988;93(5):423-8.

[9] Melrose C, Millett DT. Toward a perspective on orthodontic retention? Am J Orthod Dentofac Orthop. 1998;113(5):507-14.

[10] Littlewood, S., Kandasamy, S. and Huang, G. (2017). Retention and relapse in clinical practice. Australian Dental Journal, 62, pp.51-57.

[11] Kaan M, Madle'na M. Retention and relapse. Review of the literature. Fogorvosi szemle 2011;104:139-46. 4.

[12] Littlewood, S.J., Millett, D.T., Doubleday, B., Bearn, D.R. and Worthington, H.V. (2016) Retention procedures for stabilising tooth position after treatment with orthodontic braces. The Cochrane Database of Systematic Reviews, CD002283. doi:10.1002/14651858.CD002283.pub4

[13] Singh, P., Grammati, S. and Kirschen, R. (2009) Orthodontic retention patterns in the United Kingdom. Journal of Orthodontics, 36, 115-121.

[14] Wong, P.M. and Freer, T.J. (2004) A comprehensive survey of retention procedures in Australia and New Zealand. Australian Orthodontic Journal, 20, 99-106.

[15] Vandevska-Radunovic, V., Espeland, L. and Stenvik, A. (2013) Retention: type, duration and need for common guidelines. A survey of Norwegian orthodontists. Orthodontics: The Art and Practice of Dentofacial Enhancement, 14, e110-e117.

[16] Renkema, A.M., Sips, E.T., Bronkhorst, E. and KuijpersJagtman, A.M. (2009) A survey on orthodontic retention procedures in The Netherlands. European Journal of Orthodontics, 31, 432-437.

[17] Andriekute, A., Vasiliauskas, A. and Sidlauskas, A. (2017) A survey of protocols and trends in orthodontic retention. Progress in Orthodontics, 18, 31.

[18] Zachrisson BU. Long-term experience with directbonded retainers: update and clinical advice. J Clin Orthod. 2007;41:728-737.

[19] De Bernabé PGG, Montiel-Company JM, ParedesGallardo V, Gandía-Franco JL, Bellot-Arcís C. Orthodontic treatment stability predictors: A 
retrospective longitudinal study. Angle Orthod. 2017;87(2):223-229.

[20] Bjering R, Birkeland $\mathrm{K}$, Vandevska-Radunovic V. Anterior tooth alignment: A comparison of orthodontic retention regimens 5 years posttreatment. Angle Orthod. 2015;85(3):353-9.

[21] Al-Omiri MK, Abu Alhaija ES. Factors affecting patient satisfaction after orthodontic treatment. Angle Orthod. 2006;76:422-431.

[22] Shaw WC. Factors influencing the desire for orthodontic treatment. Eur J Orthod. 1981;3:151-162.

[23] Mollov, N.D., Lindauer, S.J., Best, A.M., Shroff, B. and Tufekci, E. (2010) Patient attitudes toward retention and perceptions of treatment success. The Angle Orthodontist, 80, 656-661.

[24] Wong P, Freer TJ. Patients' attitudes towards compliance with retainer wear. Aust Orthod J. 2005;21:45-53.

[25] Sawhney, Bhavana, "Orthodontic Retainers: A Survey of Patient Compliance and Satisfaction" (2013). Electronic Thesis and Dissertation Repository. 1917.

[26] Johnston CD, Littlewood SJ. Retention in orthodontics. $\mathrm{Br}$ Dent J. 2015;218(3):119-22. doi:10.1038/sj.bdj.2015.47.

[27] Richter DD, Nanda RS, Sinha PK, Smith DW, Currier GF. Effect of behavior modi cation on patient compliance in orthodontics. Angle Orthod 1998; 68: 123-132. doi: $10.1043 / 0003-$ 3219(1998)068<0123:EOBMOP>2.3.CO;2

[28] Tsichlaki A, Chin SY, Pandis N, Fleming PS. How long does treatment with fixed orthodontic appliances last? A systematic review. Am J Orthod Dentofacial Orthop. 2016 Mar;149(3):308-18. doi: 10.1016/j.ajodo.2015.09.020.

[29] Bichara LM, Aragón ML, Brandão GA, Normando D. Factors influencing orthodontic treatment time for nonsurgical Class III malocclusion.J Appl Oral Sci. 2016;24(5):431-436. doi:10.1590/1678-775720150353

[30] Popowich K, Nebbe B, Heo G, Glover KE, Major PW. Predictors for Class II treatment duration. Am J Orthod Dentofacial Orthop. 2005 Mar;127(3):293-300. doi: 10.1016/j.ajodo.2003.12.025. PMID: 15775943.

[31] Skidmore KJ, Brook KJ, Thomson WM, Harding WJ. Factors influencing treatment time in orthodontic patients. Am J Orthod Dentofacial Orthop. 2006 Feb;129(2):230-8. doi: 10.1016/j.ajodo.2005.10.003.

[32] Fisher MA, Wenger RM, Hans MG. Pretreatment characteristics associated with orthodontic treatment duration. Am J Orthod Dentofacial Orthop. 2010 Feb;137(2):178-86. doi: 10.1016/j.ajodo.2008.09.028.
[33] Koora K, Muthu MS, Rathna PV. Spontaneous closure of midline diastema following frenectomy. $J$ Indian Soc Pedod Prev Dent. 2007;25(1):23-26. doi:10.4103/09704388.31985

[34] Suter VG, Heinzmann AE, Grossen J, Sculean A, Bornstein MM. Does the maxillary midline diastema close after frenectomy?. Quintessence Int. 2014;45(1):57-66. doi:10.3290/j.qi.a30772.

[35] Moorrees CFA. The dentition of the growing child: A longitudinal study of dental development between 3 and 18 years of age. Cambridge (LK): Harvard University Press; 1959.

[36] Ren SS, Dai X, Ying M, Wang WX, Chang J, Hou ZM. [Factors affecting stability after fixed orthodontic treatment]. Zhonghua Kou Qiang Yi Xue Za Zhi. 2018 Sep 9;53(9):599-603. Chinese. doi: 10.3760/cma.j.issn.1002-0098.2018.09.006. PMID: 30196619.

[37] Moyers RE. Handbook of orthodontics for the student and general practitioner. 3rd ed. Chicago (IL): Year Book Publishers Inc; 1973.

[38] Chinvipas N, Hasegawa Y, Terada K. Repeated bonding of fixed retainer increases the risk of enamel fracture. Odontology. 2014;102:89-97. doi: 10.1007/s10266-012-0095-9.

[39] Maia NG, Normando D, Maia FA, Ferreira MA, do Socorro Costa Feitosa Alves M. Factors associated with long-term patient satisfaction. Angle Orthod. 2010;80:1155-

8. https://doi.org/10.2319/120909-708.1

[40] Aasen TO, Espeland L. An approach to maintain orthodontic alignment of lower incisors without the use of retainers. Eur J Orthod. 2005;27(3):209-214. doi:10.1093/ejo/cji012

[41] Al-Jewair TS, Hamidaddin MA, Alotaibi HM, et al. Retention practices and factors affecting retainer choice among orthodontists in Saudi Arabia. Saudi Med J. 2016;37(8):895-901. doi:10.15537/smj.2016.8.14570

[42] Andriekute A, Vasiliauskas A, Sidlauskas A. A survey of protocols and trends in orthodontic retention. Prog Orthod. 2017 Oct 9;18(1):31. doi: 10.1186/s40510-0170185-x.

[43] Destang DL, Kerr WJ. Maxillary retention: is longer better? Eur $\quad J \quad$ Orthod. 2003;25(1):65-69. doi: 10.1093/ejo/25.1.65.

[44] Parker GR. Transseptal fibers and relapse following bodily retraction of teeth: a histologic study. Am J Orthod. 1972;61(4):331-344. doi: 10.1016/00029416(72)90298-9. 